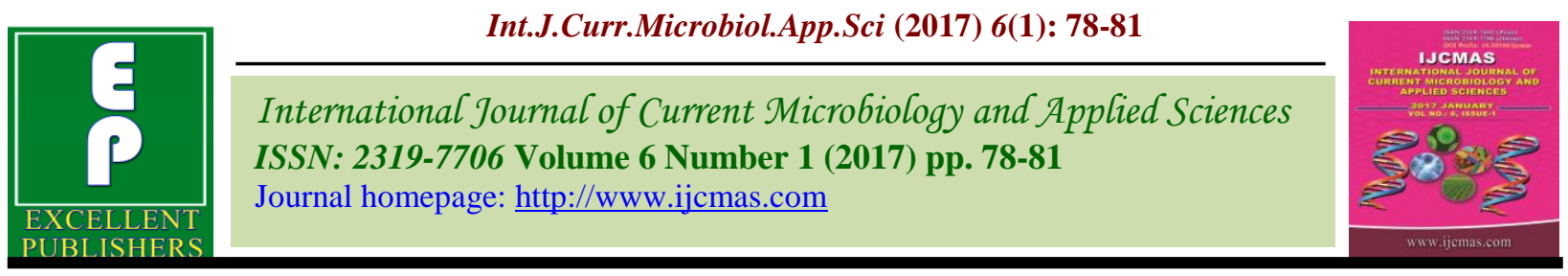

Original Research Article

http://dx.doi.org/10.20546/ijcmas.2017.601.010

\title{
Effect of Tuberculosis Co infection on Virological Failure in HIV Patients on First Line of Highly Active Antiretroviral Therapy
}

\author{
M. Rajian*, P.S. Gill and U. Chaudhary \\ PG student, Department of Microbiology, PGIMS Rohtak (Haryana)-124001, India \\ *Corresponding author
}

A B S T R A C T

Ke y w o r d s
Virological Failure,
Tuberculosis
coinfection,
HIV,
HAART.

Article Info

Accepted:

09 December 2016

Available Online:

10 January 2017

\begin{abstract}
In developing countries, Tuberculosis is the commonest coinfection to occur in HIV positive patients and is supposed to impact the treatment outcome in patients on antiretroviral therapy. This prospective study was conducted in Department of Microbiology, PGIMS Rohtak to study the effect of coinfection with TB on Virological Failure in patients on first line of Highly Active Antiretroviral Therapy. A total of 50 patients on first line of HAART and suffering from Immunological Failure were chosen and were evaluated for Tuberculosis. Plasma viral load of these patients was done to find Virological Failure patients and the effect of coinfection with TB on Virological Failure was studied. Out of 50 patients with Immunological Failure, 17(34\%) had HIV-TB coinfection. Eight out of 50 patients had Virological Failure and coinfection with TB was seen in $7(87 \%)$ out of 8 Virological Failure patients. The occurrence of Virological Failure is more likely if the patient has coinfection with TB. Prevention and timely treatment of this coinfection is vital to prevent the development of Virological Failure.
\end{abstract}

\section{Introduction}

HIV-TB co-infection is one of the most challenging issues in the effort to scale up ART since more than $60 \%$ of HIV-infected patients develop TB. Patients with TB merit special consideration because the comanagement of HIV and TB is complicated by drug interactions between rifampicin and NNRTIs and PIs, pill burden; adherence; and drug toxicity. Active TB is the commonest opportunistic infection among HIV-infected individuals and is also the leading cause of death in HIV-infected patients (NACO Guidelines, 2007). Human immunodeficiency virus type 1 (HIV) and Mycobacterium tuberculosis have become intertwined over the past few decades in a "syndemic" that exacerbates the morbidity and mortality associated with each pathogen alone. HIV leads to an increased risk of developing TB shortly after HIV infection.

It has been proposed that the increase in pathology associated with HIV/M. tuberculosis coinfection is caused by a functional disruption of the local immune response within the granuloma which may be caused byan increase in the viral load within involved tissue, leading to decrease in the total number ofCD4 $\mathrm{T}$ cells, along with a disruption of macrophage function and a perturbation of $M$. tuberculosis-specific T cell function that lead to functional and 
detrimental changes within granulomas. These disruptions presumably decrease the ability of the granuloma to contain $M$. tuberculosis, leading to increased bacterial growth with more mycobacterial dissemination and severe pathology (Diedrich et al., 2011). This study was conducted to know the effect of coinfection with TB on treatment failure in HIV patients on first line of HAART.

\section{Materials and Methods}

This prospective study was conducted in Department of Microbiology, PGIMS, Rohtak. A total of 50 HIV positive patients on first line of Highly Active Antiretroviral Therapy were chosen based on WHO criteria for Immunological Failure based on CD4 count (NACO Guidelines, 2007). All the patients, irrespective of whether they had signs and symptoms of chest infection, were screened for pulmonary TB by chest X-ray, and subsequently by repeated microscopic examination of sputum for acid fast bacillus (AFB) using standard technique. Those individuals who were positive for $\mathrm{AFB}$ in their sputum received standard directly observed therapy short-course as per revised national tuberculosis control programme of the Government of India ( WHO Report, 2008). Blood samples were collected after obtaining written informed consent. Blood samples were processed for plasma viral load testing which was done by was done using Roche Diagnostics' RT-PCR Kit (COBAS® TaqMan® HIV-1 Test). Statistical analysis was done using SPSS (version20.0)The statistical association was considered when $p$ value was $<0.05$.

\section{Results and Discussion}

Out of 50 cases, $30 \%$ were females and $70 \%$ were males; median age was 32.5 years; mean time on ART was 38.5months; mean baseline CD4 cell count was 139 cells $/ \mathrm{mm}^{3}$.The commonest first-line ART regimens were: Zidovudine/Lamivudine/Nevirapine(AZT/ZD $\mathrm{V}+3 \mathrm{TC}+\mathrm{NVP})(40 \%)$ followed by zidovudine/Lamivudine/Efavirenz (ZDV+ 3TC+EFV) ( 18\%) and Stavudine/ Lamivudine/ Nevirapine ( d4T30+3TC+NVP) $(16 \%)$. On testing for tuberculosis by various methods, it was found that $17(34 \%)$ out of 50 patients had coinfection with TB. On the basis of plasma viral load testing,8 $(16 \%)$ of the total cases had treatment failure and these were designated as virological failures while the remaining $42(84 \%)$ were classified as immunological failures only. Out of 8 patients having virological failure, $7(87 \%)$ had coinfection with TB. On the basis of these findings in the study, coinfection with TB appeared to be influencing development of Virological Failure and this was found to be statistically significant ( $p$ value <0.05) (Table 1).

Table.1 Distribution of failure cases \& TB co-infection

\begin{tabular}{|c|c|c|c|c|}
\hline $\begin{array}{c}\text { Co-infection } \\
\text { with TB }\end{array}$ & Cases & $\begin{array}{c}\text { Virological } \\
\text { Failure }\end{array}$ & $\begin{array}{c}\text { Virological } \\
\text { Failure (\%) }\end{array}$ & $p$ value \\
\cline { 1 - 3 } Yes & 17 & 7 & 41.2 & \multirow{2}{*}{$<0.05$} \\
\hline No & 33 & 1 & 3 & \\
\hline
\end{tabular}


Table.2

\begin{tabular}{|l|c|c|}
\hline \multicolumn{1}{|c|}{ Virological Failure(\%) in: } & Bello et al & Present study \\
\hline TB positive patients & 27.3 & 41.2 \\
\hline TB negative patients & 9.4 & 3 \\
\hline
\end{tabular}

In the study by Bello et al, the tuberculosis comorbidity had significant influence on the occurrence of Virological Failure. In addition, the HIV infection increases the risk of latent tuberculosis reactivation, a new infection progression or re-infection to active disease, increasing the risk of the emergence of HIV resistant strains to the usual antiretroviral therapy and thus causing treatment failure. Tuberculosis also accelerates the course of HIV induced disease by activating viral replication and accentuating the decline of $\mathrm{T}$ CD $4^{+}$cells (Bello et al., 2011). The findings of Bello et al with regard to occurrence of increased chances of Virological Failure in patients who are co-infected with tuberculosis are in congruence with our findings (Table 2) and the same are also corroborated by the studies by Ahoua et al., (2009), Bekker et al., (2003) and von Reyn et al., (2011), which also showed that the mycobacterial disease was a major contributor to HIV mortality and Virological Failure is associated with occurrence of TB coinfection. In conclusion, on the basis of the results obtained from this study, it could be observed that the likelihood of occurrence of Virological Failure may increase if the patient also develops coinfection with Tuberculosis. In such a scenario; prevention, early diagnosis and timely treatment of Tuberculosis may serve as important tool to prevent the landing of patient into Virological Failure.

\section{Acknowledgements}

Thanks to Head of Microbiology Department, Anti retrovral Therapy Centre Incharge and staff of PGIMS, Rohtak (Haryana).

\section{References}

Ahoua, L., Guenther, G., Pinoges, L., Anguzu, P., Chaix, M.L., Tiec, C.L., et al. 2009. Risk factors for virological failure and subtherapeutic antiretroviral drug concentrations in HIV-positive adults treated in rural northwestern Uganda BMC Infect. Dis., 9: 81 doi:10.1186/1471-2334-9-81

Bekker, L.G., Orrel, C., Reader, L., Matoti, K., Cohen, K., Martell, R. 2003. Antiretroviral therapy in a community clinic - early lessons from a pilot project. Afr. Med. J., 93(6): 458-62.

Bello, E.J.M., Correia, A.F., Marin, J.R.P., Merchan-Hamm, E., Kanzaki, L.I.B. 2011. Predictors of virologic failure in HIV/AIDS treated with highly active antiretroviral therapy in Brasilia, Brazil during 2002-2008. Drug Targets Insights, 5: 33-41.

Diedrich, C.R., Flynn, J.A. 2011. HIV1/Mycobacterium tuberculosis Coinfection Immunology: How Does HIV-1 Exacerbate Tuberculosis? Infection and Immunity, 79: 1407-1417.

National AIDS Control Organization. 2013. Antiretroviral therapy guidelines for HIV infected adults and adolescents including post exposure-2007.

Plasma viral load measurement byCOBAS $®$ TaqMan ${ }^{\circledR}$ HIV-1 Test, version 2.0 For Use with The High Pure System. Roche Molecular Systems. 11/2012; 05923573001-03 Doc Rev. 3.0.

Von Reyn, C.F., Kimambo, S., Mtei, L., et al. 2011. Disseminated tuberculosis in human immunodeficiency virus 
infection: ineffective immunity, World Health Organization. 2008. Global polyclonal disease and high mortality. tuberculosis control: Surveillance, Int. J. Tuberc. Lung Dis., 15(8): 1087- planning, financing. WHO Report, 92. 2008. WHO/HTM/TB/2008.393. Geneva: WHO; 2008. p. 1- 168.

\section{How to cite this article:}

Rajian, M., GillPS and Chaudhary, U. 2017. Effect of Tuberculosis Co infection on Virological Failure in HIV Patients on First Line of Highly Active Antiretroviral Therapy. Int.J.Curr.Microbiol.App.Sci. 6(1): 78-81. doi: http://dx.doi.org/10.20546/ijcmas.2017.601.010 